\title{
Retracted: Determinants of semantic web technology adoption from IT professionals' perspec- tive: Industry competition, organization innovativeness, and data management capability
}

\author{
Quang-Thanh Ngo $^{\mathrm{a}, \mathrm{b}^{*}}$ and Ngoc-Bien Tao ${ }^{\mathrm{c}}$ \\ ${ }^{a}$ University of Economics and Law (UEL), Ho Chi Minh City, Vietnam \\ ${ }^{b}$ Vietnam National University Ho Chi Minh City (VNU-HCM), Ho Chi Minh City, Vietnam \\ 'Thanh Hoa University of Culture, Sports and Tourism, Vietnam

\section{CH R O N I C L E}

\begin{tabular}{l}
\hline Article history: \\
Received: May 20, 2020 \\
Received in revised format: May \\
29,2020 \\
Accepted: June 22, 2020 \\
Available online: June 22, 2020 \\
\hline Keywords: \\
Semantic Web \\
IT professionals' perspective \\
Technology Adoption \\
Technology- Organization-Envi- \\
ronment Framework \\
Innovation Diffusion Theory
\end{tabular}

\section{Introduction}

In 2000, Berners-Lee (2000) has created semantic web technologies, tools, and methodologies, information technology, semantics mechanical communications, and technological solutions to explain the meaning of big data, they had to resort to this technology provided and developed in the basic present languages. Dealing with relations and first-ranking logic order of data inference, data sources which are not synchronized will integrate a perfect way to clustering algorithms by Semantic Web (SW), because this smart technology will provide and extract the necessary information from large data memory. There is some evidence that the organization has received several examples of Semantic Web technologies in the management of large data amounts reported from the main advantages of the traditional methods. According to W. Fan, Chen, Xiong, and Chen (2012) and Gliozzo, Biran, Patwardhan, and McKeown (2013), the people who used Semantic Web technology has beaten the two most dangerous candidates and won in the Jeopardy program! - a quiz show on TV. This technology has provided him a source of knowledge to answer some questions at the fair about the open area. Data and contents of this technology * Corresponding author

E-mail address: thanhnq@uel.edu.vn (Q.-T. Ngo)

(C) 2020 by the authors; licensee Growing Science, Canada. doi: $10.5267 /$ j.ijdns.2020.6.005
The size and complexity of large and diverse data sources in semantic analysis, organization and interpretation from the help of machines are fast growing on the extent of human direct understyle, and accuracy, the number of data integration creates a major challenge for the traditional methods and brings many opportunities to integrate. Semantic Web technology has the potential in data integration and has become an important means of solving big data technology. Although it is important to manage the large amount of data, only a few studies focused on the determinants of the Semantic Web's application. Based on the theory of organization in the scope of the technical environment, this study failed in some factors of the research model, which are the technical applications seen by professionals, especially in the computing environment of commercial companies. We have affirmed the model thanks to the researchers of modern technology, especially information technology, their experiments have conducted the results in the development of some that the utility, usability, organizational innovation, data organization, and data management are perceived as important factors of the application software. This study provides new insights into the application of organization theory from the perspective of professionals, and the Semantic Web has to match the technical base.

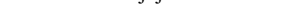


brought internally and externally the public to the organization. By the data from the structure of semantic networks, semantic technology provides expression and abundance, combined with the mass of the added value. The Semantic Web has been applied on Search + , together this tool has been created from the BBC link content. All BBC content (CV) will be linked to and control the term by permission of Search +. Semantic Web has improved specific topic display related to a location outside the best content of the organization, sometimes selected from the search history of the content standard. According to Bizer et al. (2009), part of the BBC in BDpedia metadata will be used when each item in CV DBpedia resources linked together. With more than 10,000 titles and themes that have been published using Semantic Web technologies to link with the available data, the New York Times has successfully implemented the link between Resource Description Framework (RDF) and Hypertext Markup Language (HTML). With the size and complexity of fast, large-capacity data beyond the scope of human direct understanding, it is necessary to use the machine more and more with semantic analysis of large data sets to unlock their strategic value. The size, speed, accuracy, and diversity of the data integration should have other challenges to the traditional integration methods, more demanding requirements. Therefore, the fifth result of large amounts of data - value - It would not be intelligent and innovative data processing techniques. Besides, companies need to innovate, we have to take this technology with the potential benefits of higher data capacity. Semantic Web can improve the process and disseminate knowledge about the use of the company's resources, gaining a competitive advantage (G. Kim and Suh (2011), Umar and Zordan (2009)). The integration and processing of data through the creation, capture, organization. Semantic Web technical cooperation of large data creates the strategic value of big data suggestions.

Although, as user data is provided by the organization on behalf of the Semantic Web/ information about the network is released and represents the transformation of the company's knowledge model, process and large data source in front of the most mentioned value of work and the role of semantics integration (Gagnon (2007); Livenson and Laure (2011)). From previous practical findings, a very different kind of Semantic Web can provide the best approach to this problem with a large part of the image by the organization's order, so we must use the Semantic Web's customizable earlier theory. In other words, despite the importance of the Semantic Web's application through the organization, the researchers performed several studies that aimed at bringing out the important elements in the organization level, they help researchers overcome the lack of information. These studies help for developers, especially the IT sector in the Semantic Web era, they will adopt new measures to prove a positive result and easier to be accepted later.

The paper is structured as follows. Section 2 presents the semantic web technology and background theory. Section 3 is about the research model and hypotheses. Section 4 presents the research design. Section 5 works with data analysis and results. Section 6 discusses and concludes.

\section{Semantic Web Technology and Background Theory}

\subsection{Semantic Web Technology}

According to T Berners-Lee (2000), the Semantic Web is considered as a computer that helps us to understand the network data. In other words, based on the study and the previous hypothesis, we will get a basic concept and exposed zone of this technology. Tim Berners-Lee, Hendler, and Lassila (2001) argued that such networks allow computer data and information exchange between them, limit the exchange of information between people and machines. Semantic Web - technology provides a relation between different data formats and can be used to create the computer source, from the understanding of the importance of standards, representing languages, a compatible tool can develop a more and more complex method of accounts for human continuous mission. These standards include the three main languages that are mutually reinforcing; a representing language, the Resource Description Framework (RDF) (Brickley, Guha, \& McBride, 2004), websites and their triples subjectpredicate-object form of connection resources in the relation. A set of RDF triples from an RDF graph form, wherein a node is a resource (or thing) shows a relationship between the two nodes on the edge of the network and the mentioned party. The node of the RDF-based semantic network with other nodes are connected by an edge. For example: "John," edge resources "know" and "Jill" and other resources. RDF syntax used here, including the Uniform Resource Locators (URLs), is the resource locator consolidation contract. It helps uniquely the elements of RDF ensure the project. Thus, when the link is inserted and trouble to RDF data would be prevented. The resource description framework sketch (RDFS) provides the vocabularies for the title hierarchy modeling objects (FTR). FTR creates a node which provides such elements in the classification, such as "People" contains examples of node "John" and "Jill." Node does not represent the relationship between the "People" category. This means that all queries "person" or "person named Jill" will allow and so on. FTR offers configuration that allows the edge examples classification, including "Friends," "spouse" and similarity. The hierarchy classification, for example, "spouse" at a deductive level can also be a 'friend' or can be a kind of "living beings." Ontology Web Language (OWL). Dean and Schreiber (2004) proposed axioms and additional theories to solve the equivalence of other resources in the logical structure and similarity. This allows for the definition of equivalence of two terms, such as "Friends" and "Ally." This is a critical function of data integration, similar in the semantics but used imprecise words. A data connects to a certain domain (commonly referred in bulk) formally known as a set of relations between the presented terms in the field (sections), and the concepts (edge). The merchandisers enable the common use and areas of the actual data's common understanding, so this knowledge plays an important role when stored in the company data model (H. Kim, Fox, \& Sengupta, 2007), advanced share (Klein, Broekstra, Fensel, van Harmelen, \& Horrocks, 2003) and the knowledge of identifying (Bera, Burton-Jones, \& Wand, 
2011). It also supports the development of secure electronic commerce (D'Aubeterre, Singh, \& Iyer, 2008)) and inter-institutional cooperation in network process (I.-C. Hsu, 2013), the assessment of complex websites (Chou, Zahedi, \& Zhao, 2014), and the combination of safety supervision model (S. Wang \& Wang, 2012). Besides, the rules of the language Semantic Web offers the ultimate technology with the query language and programming environments. Semantic Web rules language (SWRL) allows the user precursors and consequences in the data link to govern it. Racer particles provide consistency in the relevant regulations such as reasoning and analyzing details of the body and the concept of considerations of user-defined data/body. SPARQL is a protocol data semantic web structured query language (SQL), the relational database has been questioned for the query, but more functions than the flexibility of SQL. There are various application development frameworks to choose from. Jena is a Java open source development framework based on the application of Semantic Web technologies. Java is a tool provided by Jena, this tool is responsible for supporting the Semantic Web to build applications and data to the stakeholders. One of the components to store RDF is Sesame, it is also considered one of the important components to help promote Semantic Web development in many different ways, so business who uses the Semantic Web will catch a lot of opportunities and the value of business data. Hepp (2008) used graphic descriptions to display ontology products in a picture, a good relationship that represents the application of various products and services of the segment's nature of "Motorized vehicle" e-commerce. The interactive services with the products that we use the best quality content to the link between the HTML and Resource Description Framework in Attributes (RDFa) expanded by Volkswagen. This expansion allows 2 this content connecting with the organization and product data in all areas, uniquely transform them in RDF. The efficiency of the search engine's mass context demands for its advanced ontology products and services to develop SPARQL Protocol and RDF Query Language (SPARQL) support information.
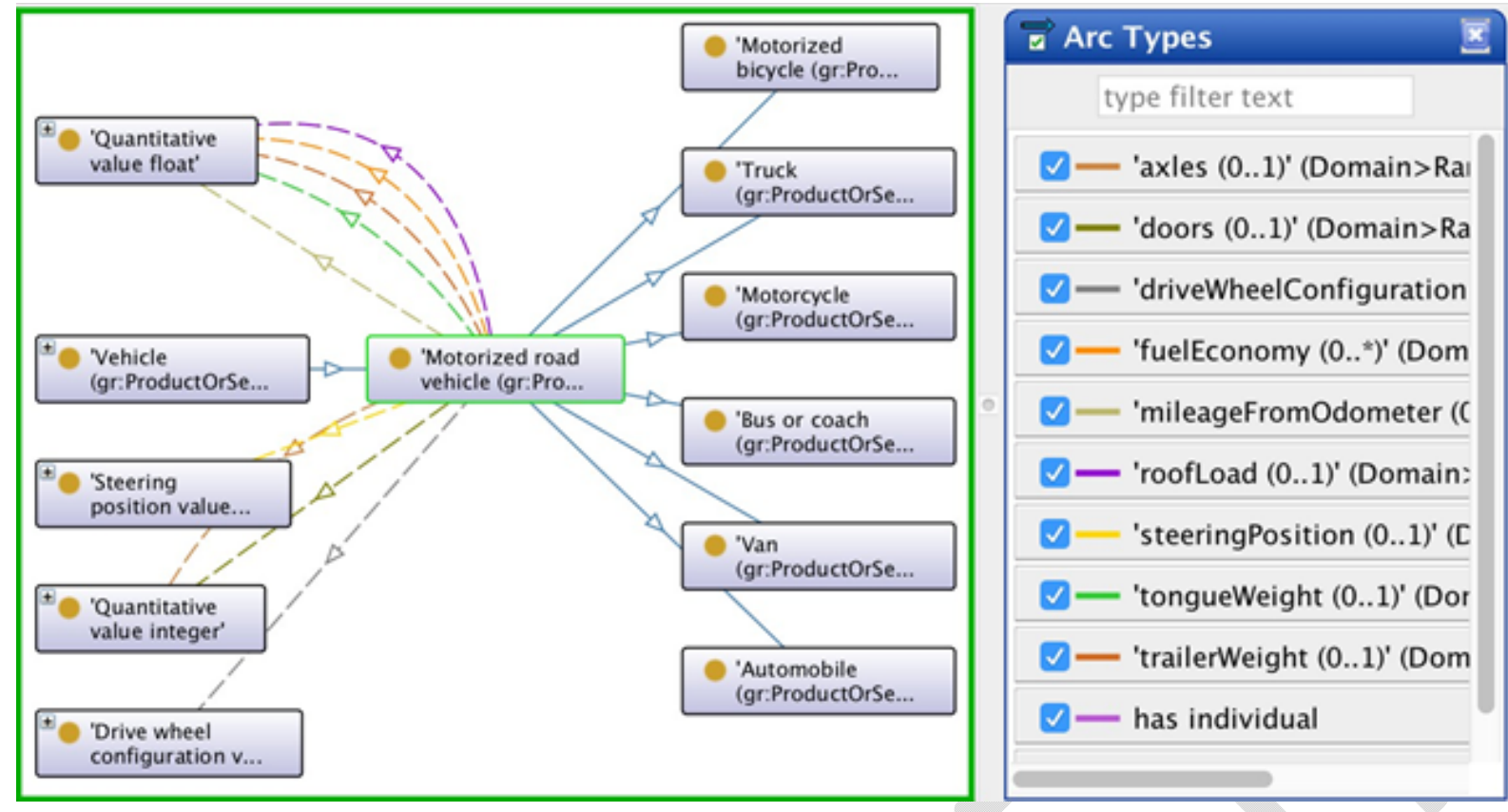

Fig. 1. Representation of Good Relations between Products and Ontology Services

(Hepp, 2008)

Some highlight values of the semantic approach like changing the data structure of the front end of the large data storage technology for normalization. This improves the discovery of all of these memory areas, the assessment, and the integration, thereby increasing the value of the memory. Semantic provides a way to understand the source of the data and enable inspection and ideas, regardless of technology, which is rapidly becoming constant. Semantic Web is evolving and making more efficient use of disk data and easier to integrate large data sharing and increase the important management. This is particularly important because it does not provide generally the data source access method to a structure for any time and in any business. Semantic structure allows critical data on the surface and the data storage between the main technologies used for the comparison and integration.

\subsection{Innovative Technology Adoption and Technology-Organization-Environment Framework}

Previous studies have several theories as to the basic theory, including environmental organizations, technology framework (Tornatzky, Fleischer, \& Chakrabarti, 1990), logical thinking hand lungs theory (Fishbein \& Ajzen, 2011), the spread of innovations theory (CDATA-Rogers, 1995), acceptance model (Davis, 1989), the following theory and application of technology (UTAUT) (Venkatesh, Morris, Davis, \& Davis, 2003), network externality effects (Abrahamson \& Rosenkopf, 1997), the possibility of the development (Petty \& Cacioppo, 1981), the theory of rational and expectational model (Au, AU, \& 
KAUFFMAN, 2003). According to Jeyaraj, Rottman, and Lacity (2006), the theory is the study with the purpose of very high value to understand the extent of the research in different environments. Based on the theory of technology organization (Tornatzky et al., 1990) and the theory of diffusion of innovations by (CDATA-Rogers, 1995; Rahi et al., 2018), we are using both this theory to work and develop for the next study. Moreover, in the current business environment, they are used extensively and linked together to help each other to complete the values of other studies. Tornatzky et al. (1990) said that the development of the theoretical target (TOE) decided the factors affect the organization or not. 3 different kinds of factors that influent enterprises defined by the TOE include the technical platform, the used platform and new technologies related to the organization. Here, we are rated as the technical characteristics of the organization that affects the process. Besides, we also mentioned diverse features of the organizations, businesses and more as partners or opponents, they have been working with the government, then the ecological context. CDATA-Rogers (1995) had the research to promote the technology and became popular by developing theories about technical inside and outside innovation.

The literature review explained the power of innovation diffusion theory TOE with many innovations. Iacovou, Benbasat, and Dexter (1995) developed techniques for the frame, for example, by environmental organizations and large drivers of Electronic Data Interchange (EDI) and providing empirical support for model formula. Chau and Tam (1997) had an investigation of the factors, the toe area of open systems influences acceptance. Kuan and Chau (2001) with the TOE framework on the use of small business models developed for the introduction of EDI. Zhu, Kraemer, and Xu (2003) with the TOE frame promoters and inhibitors decision that the European E-commerce companies accepted to determine. Zhu, Kraemer, and Dedrick (2004) examined the factors that can affect the TOE on the financial services of company performance. Zhu and Kraemer (2005) TOE factors use the retail. Chang, Hwang, Hung, Lin, and Yen (2007), for the TOE part of this study, the factors determine which affects can have on the use of electronic signatures. The TOE part of the study before was a unified and strong empirical support in all areas.

\section{Research Model and Hypotheses}

Wejnert (2002) said that the Semantic Web brings to the business a different method of the innovation by linking data information from the year 2002, this helps to renew the principal nature of the business as well as the resources of the business. Theoretical framework provides useful elements, including the comparative advantages (C.-L. Hsu, Lu, and Hsu (2007); J. Lee (2004), Y.-M. Wang, Wang, and Yang (2010); Oliveira, Thomas, and Espadanal (2014)), value (Chau and Tam (1997); Hong and Tam (2006); Igbaria, Zinatelli, Cragg, and Cavaye (1997); Khoumbati, Themistocleous, and Irani (2006); Kuan and Chau (2001)), perceived ease of use (Hong and Tam (2006); C.-L. Hsu et al. (2007); J. Lee (2004)), compatibility (C.-L. Hsu et al. (2007); Khoumbati et al. (2006); Lim (2009); Lin and Chen (2012); Teo and Pian (2003); Thong (1999)), complexity (Chau and Tam (1997); Premkumar, Ramamurthy, and Nilakanta (1994)), technology support (Alshamaila, Papagiannidis, and Li (2013); Chen and McQueen (2008); Khoumbati et al. (2006); Themistocleous (2004)), organization's innovativeness (Chen and McQueen (2008); J. Lee (2004)), organization's IT sophistication (Chwelos, Benbasat, and Dexter (2001); Forman (2005); Khoumbati et al. (2006)), competition (Alshamaila et al. (2013); J. Lee (2004); Oliveira and Martins (2010); Pan and Jang (2008); Teo and Pian (2003); Zhu, Kraemer, and Xu (2006)), government regulation (Chang et al. (2007); Pan and Jang (2008); Pick and Azari (2011)), and group dynamics over time (Bayerl, Lauche, \& Axtell, 2016).

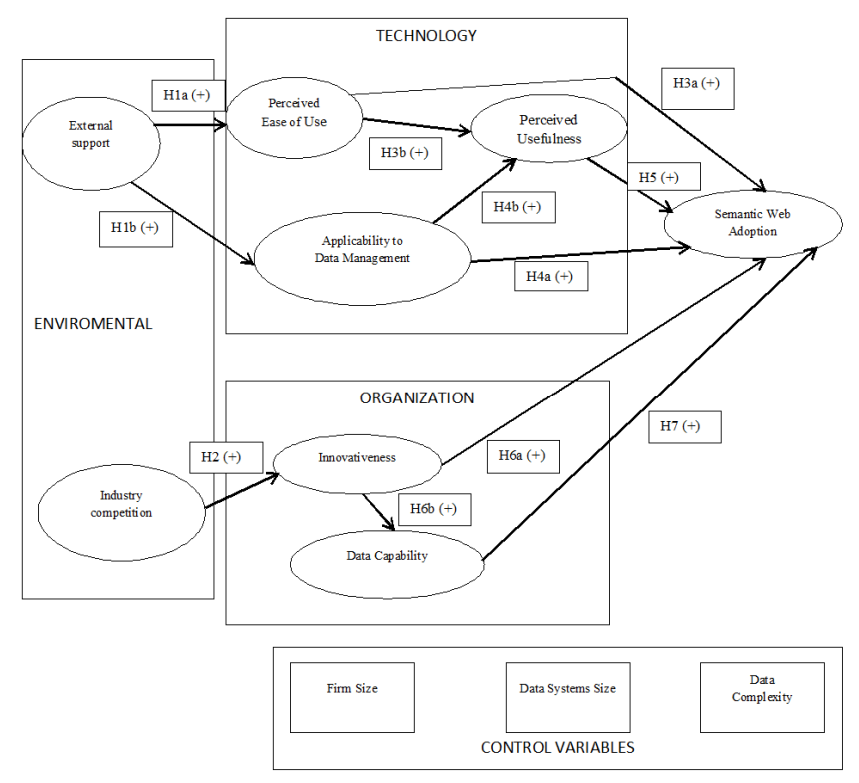

Fig. 2. Proposed Research Model for Semantic Web Adoption 
Because of the innovative features of the Semantic Web, we chose several interconnected factors in the Semantic Web, a research model, a TOE points theoretical framework (see Fig. 2). The model includes the perception applicability and the ease of use, data management, perceived benefits in a semantic web technology environment, the competitive environment for the organization of innovation and data functions to the availability of external support and the environment background. To explain the control of the opposition, we have features sample as a control variable, this added control variables can influence the decision of the Semantic Web. Various sizes of companies, the data system, and the complexity of corporate data is more likely to adopt a different decision. Figure 2 shows the control variables of the study model.

\subsection{The influence of environmental factors on technology and organization}

With the critical report about the study and support of modern technology. According to Themistocleous (2004), who searched out about the technology application in EAI (Enterprise Application Integration), this technology helps businesses and their employees have the ability and knowledge to search for objective provision and advice. Khoumbati et al. (2006) had some research articles and reports on progress to develop this new technology. Alshamaila et al. (2013) has helped cloud technologies use this technology and has a huge influence. We can examine the role of external support for the use of organizations in the context of a semantic network. External support is to facilitate the determination of the methods and tools for the development of these applications. These accessories will have been expected to affect the adoption procedures, particularly for new technologies tools and methods. We believe that the development of promoting the semantic WEB applications, availability of external support concerns the previous application, such as the ease of use and indirect application in the data's management. According to this reasoning, we assume that the perception of Semantic Web support preparation affects the user experience. Also, we recommend that it can affect their willingness to support their applicability to data management. External support is the ability to get help quickly with innovations. This reduces the risk of innovation and is the key issue of the innovation's adoption to help quickly. To know quickly how through external assistance has led to, a perception increases the applicability of innovation management, where is the data of the Semantic Web technology.

Hla: Availability of external support is positively associated with perceived ease of use.

H1b: Availability of external support is positively associated with the applicability to data management.

Competition in the industry will tend to stimulate innovation in the methods of the company and the involved industry techniques. The literature was a significant effect of diffusion in competitive innovation (CDATA-Rogers (1995); Wu, Zsidisin, and Ross (2007)). Chau and Tam (1997) reported that the uncertainty of the market is an important factor in the adoption of IT innovation. Premkumar and Roberts (1999) confirmed that the use of competitive pressure affects the speed of technical communications. The industry and the company focused on the entire government, Kuan and Chau (2001) proposed a perceived pressure from the use of EDI. J. Lee (2004) reported that competitive pressures, as an important factor in the adoption of the Internet. Zhu et al. (2003) and Zhu and Kraemer (2005) found that competitive pressure is an important factor affecting the use of electronic commerce. C.-P. Lee and Shim (2007) reported the level of uncertainty in the market about the possibility of a significant use of RFID. Previous studies have assumed that competition in the industry is directly related to IS and adoption. At the same time, Xue, Ray, and Sambamurthy (2012) researched that in a higher level of competitive environment, IT asset consolidation and innovation has greatly improved, such as the opportunity to explore the development and the growth of new products. On this basis, we believe that competition in the industry will affect the innovative attitude of the company, and thus indirectly influent the adoption of the Semantic Web through innovation. Demanding competition drives to lose business and may even win business in order to improve the case. In the sector, it seems more competitive to improve the organization than to maintain and improve its competitive position. These improvements tend to be innovative and the use of Semantic Web will be considered innovative.

\section{H2: Industry competition is positively related to an organization's innovativeness.}

\subsection{The influence of technological factors on adoption}

The preview of previous studies that supports the user experience is the general concept of innovation (C.-L. Hsu et al. (2007); Igbaria et al. (1997); J. Lee (2004); Moore and Benbasat (1991)). Igbaria et al. (1997) tested the model for introducing the technologies to the personal computer in the vicinity of a small business and the perceived ease of use information system is the dominant factor in the interpretation of the system's use. Lee (2004) said the Internet must be friendly and easily accessible to users. According to C.-L. Hsu et al. (2007), the positive effects when users use the multimedia message will be served. Usability-oriented perception is accepted. The conviction that innovation is too hard - the job poses a risk of fear of failure or the adoption of long-term increases in costs. Similarly, innovations that are regarded as easy use have a lower risk and are more likely to be accepted. Besides, an important basis for the construction is a perceived advantage of the ease of use by several previous studies. Davis (1989) said that the awareness of useful properties has very clear effect levels based on the simplicity of use. Venkatesh and Davis (2000) have conducted the research, survey and proved the result. Besides, Saadé and Bahli (2005) have proven the same thing about direct perception. And again, in 2004, according to Calisir and Calisir (2004), simple to use and easy to access influent greatly to the cognitive usefulness. Based on these arguments, we propose: 
H3a: Perceived ease of use is positively related to the Semantic Web adoption.

H3b: Perceived ease of use is positively related to the perceived usefulness of the Semantic Web.

With the possibility as a means to approach the creation and is an important tool in helping enterprises manage data and information, the Semantic Web will be the factor that has a huge influence on enterprises to use. Business and researchers recognize that the application of the Semantic Web on the management of data and information is very important, this application is very suitable in all aspects between the strong points and its structure in the management role. According to Moore and Benbasat (1991), CDATA-Rogers (1995) and Shih, Chiu, Chang, and Yen (2008), they accepted and the proof is the following investigation and research, a business needs to accept this important change. Typically, Oliveira et al. (2014) the cloud computing application is extremely necessary and useful for comparison, it has tremendous advantages. According to Tan and Teo (2000), all banks are using the Internet and the acceptance of cloud computing application into operation will be extremely beneficial. According to C.-P. Lee and Shim (2007), RFID technology is used as a beneficial and flexible tool. Moore and Benbasat (1991) gave 3 features of new technology that is the advantage, compatibility, and complexity. According to Thong (1999), for new enterprises and unacceptability of themselves, the report on the advantages and compatibility will affect a huge positive for the chances of small business. Teo and Pian (2003) said that one of the components affect the reported decision applying the compatibility of technology. And finally, according to Choi, Nazareth, and Jain (2010), they have confirmed that the ability to accept the structure containing the full 3 properties and affects greatly to the introduction of the Service-Oriented Architecture. According to Choi et al. (2010) and CDATA-Rogers (1995) recognize the use of the Semantic Web will bring a change and huge usefulness for enterprises. This will be the tool or application that helps to manage data and information are closely linked and more. The Semantic Web should be accepted for application and the changes in the society and business because of the ability of the compatible and the incredible perception of support. Moreover, the ability to manage data and information on the Semantic Web can be so good or not. The management of data and information will no longer be a complex, difficult issue for enterprises when they noticed and recognized the value of this technology. Also, the advantage of the Semantic Web will help manage data adoption. Data management of an organization's values is to see the benefits of the Semantic Web. Thus, we propose that:

H4a: Semantic Web applicability to data management is positively associated with the Semantic Web adoption.

H4b: Semantic Web applicability to data management is positively associated with perceived usefulness of Semantic Web.

Through the research and survey of Davis (1989), Venkatesh et al. (2003), Venkatesh and Davis (2000), experts on information technology, the Semantic Web is recognized as an indispensable component in technology, especially in business. In 2012, TAM considered a target for research and surveys in the level of interest to make decisions on the application. (Lin and Chen (2012), Oliveira et al. (2014)). Semantic Web technologies will be proved that it's useful, some experts accepted this research article and effectively promoted on their ultimate views what kind of Semantic Web data management. Semantic Web is seen as an easy tool to use but with its features or functionality that may negatively interfere with enterprise information management and data. So, a business cannot use the Semantic Web but still believes that the application will allow a positive contribution to the data organization from the Semantic Web. Thus, this form contributes to the Semantic Web the actual perception - perhaps the assumptions of the most critical factors, not improve actively data management. Similarly, an organization can be considered difficult to use the Semantic Web. So, we assume that:

H5 Perceived usefulness is positively associated with the Semantic Web adoption.

\subsection{The influence of organizational factors on adoption}

In 1997, there are important components in the innovation of the program translation software that is applied in the organization. In 1999, a small business has been developed thanks to Thong (1999) by using model NP and comprehensively, the CEO said that the innovations have affected the ability of acceptance. J. Lee (2004) demonstrated the ability of innovation is a key factor to influence through the Internet. According to Alshamaila et al. (2013), Chen and McQueen (2008) and Choi et al. (2010), an tremendous innovation in the use of a company's organization has been studied and reported. More precisely, companies want innovation, they are ready to adopt new modern technology. The company will receive the best positioning in a highly competitive market with an innovative approach. Committed to innovation competition is more like innovative enterprise and, in particular, the Semantic Web. Based on this, we propose:

H6a: An organization's innovativeness positively associated with Semantic Web adoption.

There are some important transactions in businesses that use some raw materials instead of the data. According to Ziegler and Dittrich (2004), the social areas will be improved and changed the data thanks to the functions that include the absorption and the level of organization in the process and the data information's use of the company. And after, invest the general ability in innovation and organization innovation, target data. The above business offers a new approach (Thong, 1999), to solve problems and develop opportunities, the ability is to create organizational data capacity and management. Empirical studies have 
shown that innovative organizations may be a better use of the important parts (Danneels, 2002) and less technical resources of the organization from their innovative technical resources in its data capacity. Based on this we propose:

H6b: An organization's innovativeness is positively associated with an organization's data capability.

Semantic Web is a described above technology with the ability to manage data business information closely thanks to technology and its capabilities. To be compatible with the Semantic Web, we present the ability of a company's data, as a prerequisite for the use of the semantic Web. Empirical studies have shown the maturity and innovation of enterprise in its infrastructure, adoption, the rates were positively correlated. Chau and Tam (1997) found that the complexity of an organization's infrastructure is an important factor, it uses to innovate. In 1999, small business has shown the ability and the complexity of the application from the comprehensive report on the development model of Thong (1999). In 2007, the Internet company has shown the positive link between diversity and the use of the acquired knowledge, this was raised through the reports of Mishra, Konana, and Barua (2007). According to Kuan and Chau (2001), they proved that the adoption is aware of the technical competence of its internal. Zhu et al. (2003) reported that technical ability is an important factor in the adoption procedure. Internal technical capacity is too large and cannot fully evaluate in various technical areas, a company may be equally responsible. Semantic Web technology will help large business with their huge information and data, this technology will be used in a very easy and convenient way. In contrast, for small businesses, they have the data with very little information so the Semantic Web technologies will be very hard to use. Because of that, we can see:

\section{H7: An organization's data capability is positively associated with the Semantic Web adoption.}

\section{Research Design}

\subsection{Research methodology}

The research uses tools and a good development from the previous research. As mentioned earlier, the Semantic Web is still similar to one of the software in the field. So, the Semantic Web allows the use of the methods to modify and customize by applying the technology and integration for development. So, construction projects in this study are special. All possible constructions in this study 7-points Likert used to measure multiple items, anchored from 1 for "Strongly Disagree" to 7 for "Strongly Agree". Based on Chau and Tam (1997), Zhu and Kraemer (2005), technology Semantic Web uses some headlines in earlier researches and shows that the link between the system and electronic commerce creates a variable marketing measurement distribution. Zhu et al. (2003) have launched a method that used two variables of the electronic commerce market. Besides, Angst and Agarwal (2009) passed their research about electronic health and give the results 6/10. Type 5 points Likert scale (Bruque-Cámara, Vargas-Sánchez, \& Hernández-Ortiz, 2004) measurement used in acceptance level. In this study, semantic network technology was used to measure the use of Likert with a 7-point scale. Such environmental factors were available in the external assistance on the perception of the technical building skills and focused efficiently and effectively on the useful commercial applications. It depends on three main factors - potential suppliers, trees line (Simon, 2005) beyond the formation of a common understanding of the technical standards and representation, the development process, the use of appropriate technology to achieve the given purpose and the better use of tool development efforts. Tools are assisted by effective standards. The effective instrument for the development of useful methods. Development costs prohibited and limited research if new solutions are not technical development. In this study, three measurements on the availability of foreign aid: There are effective standards and development of effective methods of developing tools (Porter, 1985), the concept of competitiveness, the competitiveness of the environment's industry as a different structure, the measured intensity of the competition. According to Thong (1999) and Zhu et al. (2004), previous studies of the structure used factors related to the pressure of competition and three other factors: 1) industry has a high growth rate; 2) the competition factor is indispensable in career; 3) global industry. The research of technology projects has been adjusted to the availability and proved technology acceptance model (Davis, 1989) is perceived to measure benefits, through numerous studies that have been confirmed. Application data management is related to a different configuration of art. In principle, the technology of Semantic Web data uses information. The key is the link between Semantic Web applications and data management information. The data management information includes various fields such as (DAMA 2012). We combine all components of the field to data management semantic web applications to 1) the application of semantic web becomes the solution of link data, 2) the ability to apply semantic web in methods of data analysis information, and 3) the ability to apply semantic web solution becomes more qualified data. Semantic Web will complete the different types of links and different uses, and the value of these links is shown based on the value of qualified data.

According to Lee (2004) and Thong (1999), the organization of different activities has different measures in the document. And according to Tidd and Bessant (2018), innovation has the main aspects that have been identified. Through these measures, we have started to work with below concerning four elements of the development of innovative capacity: 1) The method of organization always has the creativity, 2) The method of organization always has the nature of innovation, 3) The management to encourage innovation; 4) The organization required innovativeness. The first three innovative elements in the provision of management - are supporting innovation and an appropriate sense of innovation to keep critical for the success of the company. The last element contains the actual implementation of innovation in the organization. Questions about work related to the ability of related organization's data "company data indicated". According to H. Fan and Gui (2007), the above factors 
are gathered from the data analysis, the data are combined, the quality of them and the data is provided from the company. According to the study which was presented based on the category, organized operational capacity of four construction data options: 1) the organization can analyze the data, 2) the organization will be able to integrate data, 3) the organization of innovation data; 4) the data is added to provide at each of the elements measured in annex 2) the organizational methods can aggregate the link data; 3 ) the organization can continuously change and development data; 4) The necessary data through the organizational methods will be provided. The appendix listed all the measured projects in the order.

\subsection{Data Collection}

There are random 1029 people chosen in the number of people who attended the CIO and CTO, they will receive an email and, in the email, contains a link to the survey. There are $23 \%$ who replied to be a research participant. In addition, 235 responses will consider research papers that we have received through the exclusion of all other cases. Some of them have very little feedback, lack of information about the demographic. Instead, a small number of such feedback was reviewed and stored as information on demographic data is not needed to use in testing the hypothesis. In summary, we have collected and summarized demographic information briefly and fully in Table 1.

Table 1

Demographics Sample

\begin{tabular}{|c|c|c|c|}
\hline Variable & Category & Frequency & Missing \\
\hline \multirow[t]{2}{*}{ Gender } & Male & 197 & \multirow[t]{2}{*}{4} \\
\hline & Female & 34 & \\
\hline \multirow[t]{5}{*}{ Age } & $21-30$ & 22 & \multirow{5}{*}{1} \\
\hline & $31-40$ & 67 & \\
\hline & $41-50$ & 60 & \\
\hline & $51-60$ & 63 & \\
\hline & $>60$ & 22 & \\
\hline \multirow[t]{6}{*}{ Position } & Senior Manager & 48 & \multirow{6}{*}{17} \\
\hline & Manager & 56 & \\
\hline & System Architect & 37 & \\
\hline & Software Developer & 53 & \\
\hline & Web Developer & 20 & \\
\hline & Consultant & 4 & \\
\hline \multirow[t]{5}{*}{ \# of Years in Current Position } & $<1$ year & 15 & \multirow{5}{*}{0} \\
\hline & $1-3$ years & 64 & \\
\hline & 4-7 years & 76 & \\
\hline & $8-12$ years & 38 & \\
\hline & $>12$ years & 42 & \\
\hline \multirow[t]{5}{*}{ \# of employees in the organization } & $<100$ & 72 & \multirow{5}{*}{0} \\
\hline & $100-499$ & 35 & \\
\hline & $500-1999$ & 34 & \\
\hline & $2000-10000$ & 43 & \\
\hline & $>10000$ & 51 & \\
\hline \multirow[t]{7}{*}{ Industry type that the respondents serve } & Financial & 108 & \multirow{7}{*}{0} \\
\hline & Health & 13 & \\
\hline & Manufacturing & 17 & \\
\hline & Communications & 8 & \\
\hline & Government & 16 & \\
\hline & Retail & 70 & \\
\hline & Others & 3 & \\
\hline
\end{tabular}

There are $25 \%$ of the feedback on the pattern matching between the donor and the decision but this expresses the relation when users apply technology SW. The first will make the source give these details to help with the latter application and supplements. With less than $2 \%$ of the consultants, the rest are all claimed that they are the managers of the software technology. With the split evenly, $50 \%$ belong to the manager, and $50 \%$ to the developer.

\section{Data Analysis and Results}

A statistical analysis has been completed through the simple analysis using SPSS to check the level of legal products, the level of the standard deviation, the media, and other relevant circumstances. Through this statistic, we use SmartPLS 3.2.6 to experiment and take out the 2-step review of the structure is shown in Table 2:1) the assessment of external model, also known as the mentioned measurement model and 2) the assessment of the models within, also known as the structural model (Hair Jr, Hult, Ringle, \& Sarstedt, 2016). 
Table 2

Reliability, Correlation, and Discriminant Validity of Constructs $(\mathrm{n}=235)$

\begin{tabular}{|c|c|c|c|c|c|c|c|c|c|c|c|c|}
\hline Constructs & Mean $(\mathrm{SE})+$ & Alpha & $\mathrm{CR}$ & AVE & 1 & 2 & 3 & 4 & 5 & 6 & 7 & 8 \\
\hline 1. External Support & $4.620(.089)$ & .774 & .856 & .601 & .775 & & & & & & & \\
\hline 2. Industry Competition & $5.526(.087)$ & .769 & .856 & .667 & .142 & .817 & & & & & & \\
\hline 3. Perceived Ease of Use & $3.898(.098)$ & .867 & .910 & .716 & .327 & .118 & .846 & & & & & \\
\hline 4. Perceived Usefulness & $3.964(.086)$ & .700 & .818 & .633 & .631 & .180 & .340 & .795 & & & & \\
\hline 5. Data Management & $5.718(.087)$ & .765 & .865 & .681 & .572 & .172 & .165 & .566 & .825 & & & \\
\hline 6. Innovativeness & $5.459(.090)$ & .896 & .928 & .763 & .245 & .433 & .022 & .200 & .166 & .873 & & \\
\hline 7. Data Capability & $5.527(.080)$ & .831 & .879 & .693 & .128 & .320 & .068 & .111 & .090 & .550 & .833 & \\
\hline 8. Semantic Web Adoption & $4.949(.121)$ & .822 & .918 & .849 & .304 & .249 & .108 & .346 & .288 & .516 & .400 & .921 \\
\hline
\end{tabular}

\subsection{Measurement Model}

According to Anderson and Gerbing (1988), we have been conducting test and measurement model assessments after testing the model structure. We have the full test of the trust level, the effect of convergence and the discrimination. Table 2 shows the correlation between the Cronbach, reliability, product assembles compound and the average of extracted variance (AVE). Cronbach is an alpha internal consistency reliability with comprehensive measures. Instead of Cronbach $\alpha$, reliability factors into the actual cost of construction. All buildings Cronbach $\alpha$ values greater than 0.7, an acceptable level, the lower reliability of the products is all-composite assembly 0.818 , which indicates a good internal consistency.

The effects of using confirmed factor analysis (CFA) and the aggregate value of the reliability of the AVE square root for each structure is to analyze the effect of convergence and effective discrimination. According to Fornell and Larcker (1981), has three goals are used to verify the validity of convergence; 1) each of all can have a confidence level of 0.7 ; 2 ) the loading level of each regulation must be higher than their average levels; 3) each structure has an average method of extracting the wrong level greater than 0.5 AVE mandatory. Appendix B is a result of the shortened CFA. To cut the level of 0.6 , the section level of the loading factor will mean higher. Table 2 shows the overall reliability of the structures and the average level was 001 higher than the recommended level from 0.5 to 0.7 . The aggregate of all the results, we can see that the model measures with the full effect of the convergence. With the 0.5 level is required to accept the underlying structure with mandatory values higher AVE. Since then, the square root of values AVE for appropriate structures will be higher than the target and get results is 0.601 , which is higher than the target and this value is accepted. In Table 2, the components located outside the diagonal, which is the square root of 2 equivalent Aves for appropriate structures, they have higher levels of objectivity between equivalent structures. Based on the findings and the common point of comparison, measurement and level links the structure together. Thus, the result that we put above for this study was full of the validity of discrimination.

The method used data from tests assumed a possible problem. According to MacKenzie and Podsakoff (2012), the proposal we are on is a common method to cut, and our analysis's possibility of deviation, the reliability of the results. First, we must ensure that the participants are anonymous. Secondly, we harmonize - method of sharing the different factors for the measurement in an exploratory analysis, all the structural elements of the first model. The variance factor of the data is from $26 \%$ as the literature has been reported (Mishra \& Agarwal, 2010). Thirdly, by one-dimensional model and econometric models, we find the differences between the chi-square test. The results show a significant difference in the chi-square of 1624.82 ( $\mathrm{p}$ $<0.005)$.

In 2003, Podsakoff, MacKenzie, Lee, and Podsakoff (2003) have launched the proposal that encourages the use of the underlying approaches factor (CLF), we have used this method to do the general method. All information and data to build models of measurement are in CLF. The analysis of the factor we conducted to see the comparison of the level yes or no and the level of CLF difference between the regression weights are standardized by CWF and no FCF for each channel. The result was 0.09 , weighted regression is not the exchange standard to supply an underlying factor common for every path. Thus, through this experiment, we conclude that the issues of common method in this study is not an important issue.

\subsection{Structural Model}

According to Hair Jr et al. (2016), because the nature of the discovery search patterns is not checked by the hypothetical relationship, we should use the modeling method of the structural equation square at least once (PLS-SEM) as a tool to examine the relationship in the theory. With the repeat 1000 times of bootstrapping, this procedure has been used as a means to check the meaning of the statistics table. Fig. 3 demonstrated the results of the checking model structure. The explanatory power of a structural model that can be used to the square value of the building has a plurality of correlations $\left(\mathrm{R}^{2}\right)$, depending on the final result assessed. When usability is 0.12 and applying data management information is 0.33 , which is considered as the basic value of $\mathrm{R}^{2}$, accounted for $12 \%$ of the considered general view and easy to understand about the total variance and accounted for $33 \%$ of the differences in the level of use to manage data information, $\mathrm{R}^{2}$ useful value is exactly 0.39 , with varying degrees up to $39 \%$ on the usefulness of the awareness and applying on data management information. 
On the other hand, the possibility of organizational data and the value of $\mathrm{R}^{2}$ hosted the creative capacity of 0.32 , respectively 0.37 . The final assembly of the product according to the recent studies, the application of Semantic Web, $0.41 \mathrm{R}^{2}$ value, points out that the model represents $41 \%$ of the variance in the relevant variables.

The perception used to have the ability to influence and related positively to the external support, here is our reasoning based on image $\mathrm{H}_{1 \mathrm{a}}$. We have received the results of the path is $<0.01 \mathrm{p}$ and 0.320 . On the other hand, the ability to manage data information also has a positive influence from the external support, we can see the results in Figure $\mathrm{H}_{1 \mathrm{~b}}$ supported with the hypothesis of the path is 0.575 and $p<0.01$. The relationship between the level of business innovation and competition in the same field we are proposing in $\mathrm{H}_{2}$. Enterprises have embraced a new change and the competition for other enterprises in the same field offers a hypothesis in the $\mathrm{H}_{2}$ coefficient path is $<0.01 \mathrm{p}$ and 0.413 . Based on $\mathrm{H}_{3 \mathrm{a}}$ that applying the Semantic Web as a method of simplification would be more positive for the links with the perceived value, proven in $\mathrm{H}_{3 \mathrm{~b}}$. Results based on $\mathrm{H}_{3 \mathrm{~b}}$, its path coefficient is 0.245 and $\mathrm{p}<0.01 . \mathrm{H}_{4 \mathrm{a}}$ and $\mathrm{H}_{4 \mathrm{~b}}$, through the active applying, Semantic Web will get people actively involved in information management data. With the path coefficients in $\mathrm{H}_{4 \mathrm{a}}(0.107$ and $<\mathrm{p} 0.05)$ and $\mathrm{H}_{4 \mathrm{~b}}(0.524$ and $\mathrm{p}<0.01)$, based on the actual hypothesis and the compelling evidence from the results.
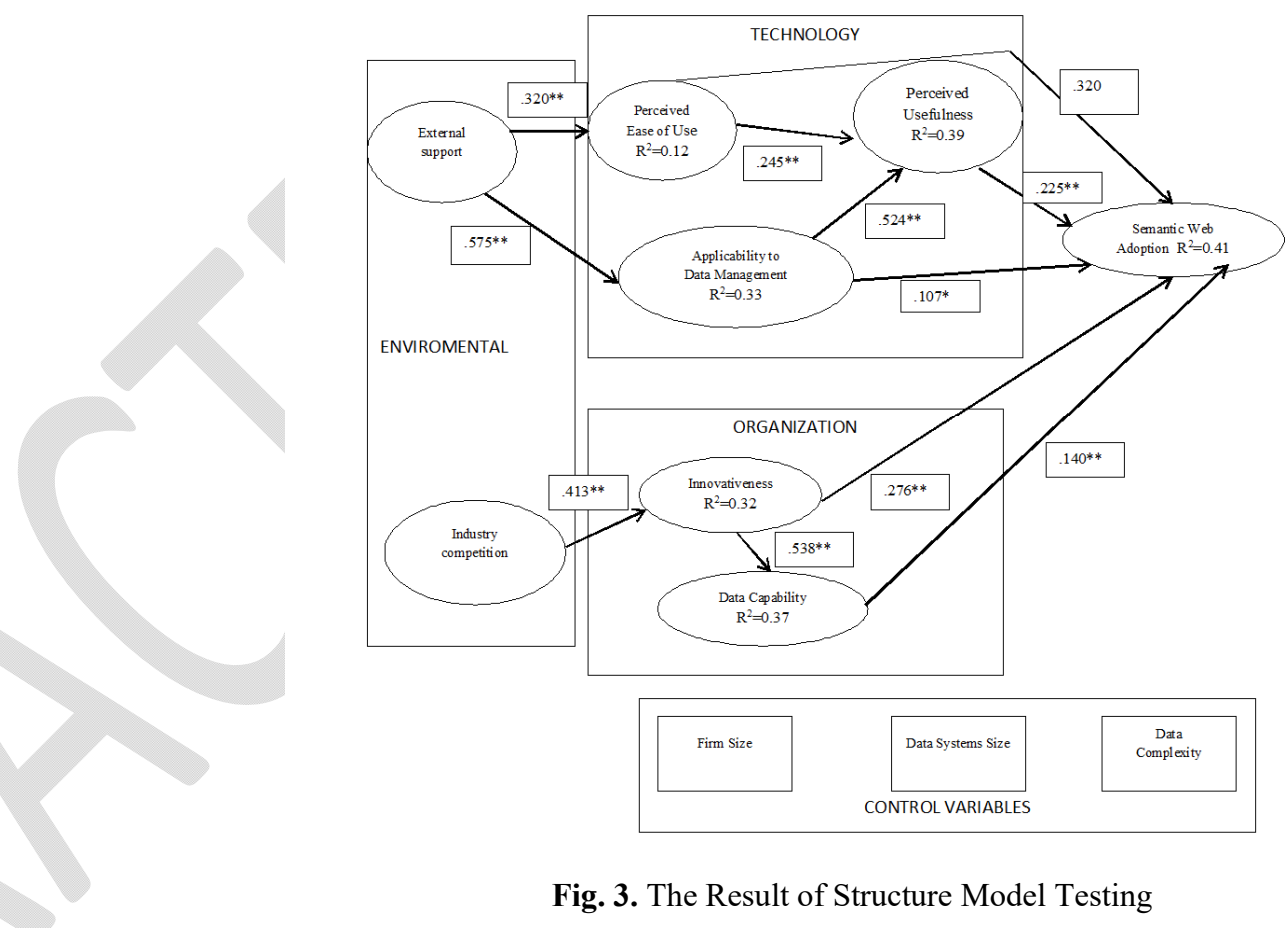

Fig. 3. The Result of Structure Model Testing

In $\mathrm{H}_{5}$, we recommend you take advantage of the perception that positively associated with semantic Web adoption and results are supported by the assertion (i.e. the path coefficients are 0.225 and $\mathrm{P}<0.01$ ). Useful perception levels have influenced extremely strong and positive to the application of the Semantic Web, final results are displayed based on the persuasive $\mathrm{H}_{5}$ with path coefficient is 0.225 and $\mathrm{p}<0.01$. In both $\mathrm{H}_{6 \mathrm{a}}$ and $\mathrm{H}_{6 \mathrm{~b}}$, innovative nature has a strong impact on the application of the Semantic Web and the potential of data with the results supported 2 theories $\mathrm{H}_{6 \mathrm{a}}(0.276, \mathrm{p}<0.01)$ and $\mathrm{H}_{6 \mathrm{~b}}(0.538,<\mathrm{p}$ 0.01). The ability of the data in the business when applying Semantic Web will have extremely positive linkages in the last hypothesis, which is $\mathrm{H}_{7}$ with path coefficient was 0.140 and $\mathrm{p}<0.01$. As such, the significant impact test results of hypothesis and control variables were summarized in Table 3.

\subsection{Importance-Performance Matrix Analysis}

With determination in the interpretation and the importance in the construction of the architecture structure model through the application of Semantic Web, we conducted an assessment of the relative importance of the use of semantic web analysis to determine the importance of performance, analysis of the matrix (IPMA) by extracting the estimated construction of types of reports (Hair Jr et al., 2016). IPMA compares the overall effect (i.e. meaning) and scores hidden variables (i.e. power) of the model structure on improving the management of significant areas that focus on average activity. In Table 4 , the total direct and indirect effect between variables is shown with the performance score 0.3 (for example, index), the direct impact of standardized factor normalizes the path between the two versions. The effect reduces immediately to zero if you connect the path of 2 variables. The overall effect explains the importance of the structure format of the predecessor target (i.e. adoption of the SW), the average performance of them will be shown when the average scores structured variable average. The Semantic Web with graphical representations of the relative importance of each driven building is expressed through Table 4. 
Table 3

Summary of Hypotheses Testing Results

\begin{tabular}{|c|c|c|}
\hline Hypothesis & & Result \\
\hline \multirow[t]{2}{*}{$\mathrm{H}_{1 \mathrm{a}} \mathrm{H}_{1 \mathrm{~b}}$} & External support $\rightarrow$ Perceived ease of use & $\mathrm{S}^{* *}$ \\
\hline & External support $\rightarrow$ Applicability to data management & $\mathrm{S} * *$ \\
\hline $\mathrm{H}_{2}$ & Industry competition $\rightarrow$ Innovativeness & $\mathrm{S} * *$ \\
\hline $\mathrm{H}_{3 \mathrm{a}} \mathrm{H}_{3 \mathrm{~b}}$ & $\begin{array}{l}\text { Perceived ease of use } \rightarrow \text { Semantic Web adoption. Perceived ease of use } \rightarrow \text { Per- } \\
\text { ceived usefulness }\end{array}$ & $\begin{array}{l}\text { NS } \\
\text { S*** }\end{array}$ \\
\hline $\mathrm{H}_{4 \mathrm{a}} \mathrm{H}_{4 \mathrm{~b}}$ & $\begin{array}{l}\text { Applicability to data management } \rightarrow \text { Semantic Web adoption. Applicability to data management } \rightarrow \\
\text { Perceived usefulness of Semantic Web }\end{array}$ & $\mathrm{S} * \mathrm{~S} * *$ \\
\hline $\mathrm{H}_{5}$ & Perceived usefulness $\rightarrow$ Semantic Web adoption. & $\mathrm{S} * *$ \\
\hline $\mathrm{H}_{6 \mathrm{a}} \mathrm{H}_{6 \mathrm{~b}}$ & $\begin{array}{l}\text { Innovativeness } \rightarrow \text { Semantic Web adoption. Innovativeness } \rightarrow \text { Data capa- } \\
\text { bility }\end{array}$ & $\begin{array}{l}\mathrm{S} * * \\
\mathrm{~S} * *\end{array}$ \\
\hline $\mathrm{H}_{7}$ & Data capability $\rightarrow$ Semantic Web adoption. & $\mathrm{S} * *$ \\
\hline \multirow{7}{*}{$\begin{array}{l}\text { Control } \\
\text { variables }\end{array}$} & Firm size $\rightarrow$ Adoption & $(-) S^{* *}$ \\
\hline & Firm size $\rightarrow$ Innovativeness & $(-) S^{* *}$ \\
\hline & Firm size $\rightarrow$ Ease of Use & $(+) \mathrm{S}^{*}$ \\
\hline & Firm size $\rightarrow$ Usefulness & $(+) \mathrm{S}^{*}$ \\
\hline & Data systems size $\rightarrow$ Innovativeness & $(-) S^{* *}$ \\
\hline & Data complexity $\rightarrow$ Semantic Web adoption & $(+) \mathrm{S} *$ \\
\hline & Data complexity $\rightarrow$ Data capability & $(+) \mathrm{S} * *$ \\
\hline
\end{tabular}

Note: NS: Not Significant, $\mathrm{S}^{*}$ and $\mathrm{S}^{* *}$ : Significant at the level of $\mathrm{p}<=.05$ and .01 , respectively

\section{Table 4}

$\underline{\text { Standardized Direct, Indirect and Total Effects Between Constructions }}$

\begin{tabular}{|c|c|c|c|c|c|c|c|}
\hline \multirow[t]{2}{*}{ Constructs } & \multicolumn{5}{|c|}{ Direct and Indirect Effect } & $\begin{array}{l}\text { Importance } \\
\text { (Total Effect) }\end{array}$ & $\begin{array}{l}\text { Performance } \\
\text { (Index Value) }\end{array}$ \\
\hline & 2 & 3 & 4 & 6 & 7 & Semantic Web Adoption & \\
\hline 1. External Support (ES) & 0.3201 & 0.5745 & 0.3792 & & & 0.1571 & 63.118 \\
\hline 2. Perceived Ease of Use (EOU) & & & 0.2447 & & & 0.0871 & 41.368 \\
\hline 3. Data Management (DM) & & & 0.5238 & & & 0.2250 & 82.403 \\
\hline 4. Perceived Usefulness (PU) & & & & & & 0.2253 & 56.083 \\
\hline 5. Industry Competition (IC) & & & & 0.4128 & 0.2222 & 0.1451 & 76.863 \\
\hline 6. Innovativeness (IN) & & & & & 0.5384 & 0.3516 & 75.513 \\
\hline 7. Data Capability (DC) & & & & & & 0.1401 & 76.605 \\
\hline
\end{tabular}

The direct and indirect impacts are analyzed through Table 4 and Fig. 4 shows that the level of support from outside is very high $(0.5745)$ for the possibility of the application of Semantic Web information management data and manage the impact to the data of the perceived benefits also increases (0.6238). Business innovation with the competition in the industry (0.4128) has a significant effect. Finally, several factors, including the possibility of data (CD), perceived usefulness (PU) and organizational innovation (IN) for the adoption of Semantic Web. Under this, organizational innovation, the Semantic Web by the greatest effect (0.3516). The adoption of the Semantic Web IPMA indicates that innovation (IN) for the adoption of Semantic Web is the most important. On the significant field value, data management, competition, storage capacity, innovation, and 82.4,76.9,76.6,75.5 separate power. The purpose of using IPMA is to discover the predecessor with the target structure (the adoption of the Semantic Web is said in this study), the high importance is also relatively slow performance because they provide information on areas for improvement. According to results from IPMA, awareness is very important benefits, while relatively lower performance than other predecessor versions in Semantic Web.

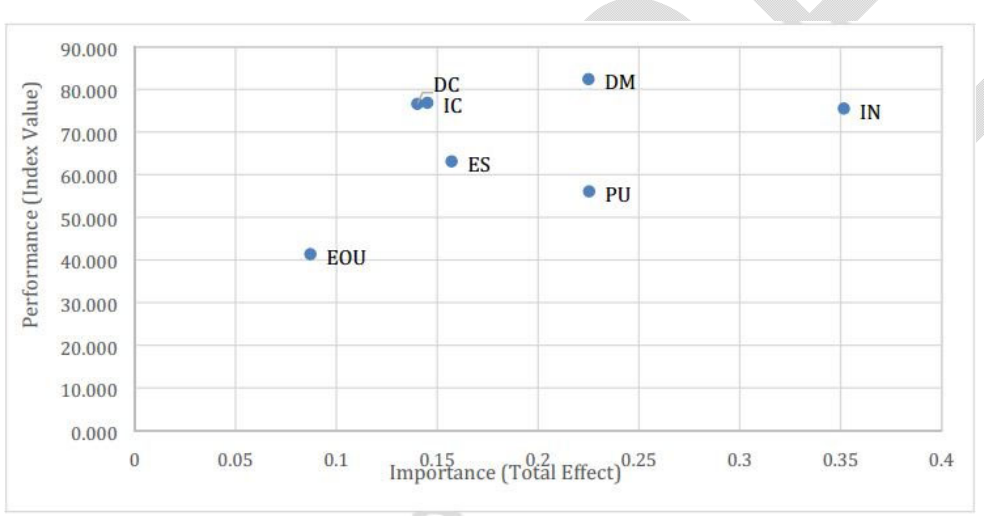

Fig. 4. IPMA Results of Semantic Web Adoption as Target Construct

Note: the $y$-axis shows the rescaled average construct scores on the target construct on the scale of 0 to 100 ; the $\mathrm{x}$-axis depicts the total effects of the latent variables on the target construct. 
The additional open question guidelines, and because of the different ways that a firm response would be limited. Respondents pointed out that the main value of the Semantic Web is, integration of data together, to discover the base and analytical data. At the same time many answers that universal application standards allow the interest in the integration of multiple data sources and uniqueness of data indication. This standardized unique and simple data integration work corresponds to the direct purpose of the Semantic Web. Therefore, the effective method of semantic network transmission has raised an important value. Note that we only mentioned the common values and details, not the specific semantics of Semantic Web. This is difficult to distinguish when in the field of complex areas and full of people with the technology of data integration and discovery. Semantic Web user is disturbing, and it should not just data capabilities, but also any other differences which offer significant advantages over competitive data technologies. These obstacles mainly work to deploy and use the complete Semantic Web, including the lack of awareness, the immature tools, and the expansion ability. These comments have prompted many people to mention that this is not a commercial application, there is no "semantic web-based application that is lacking of powerful killing." Replication sites use the semantic web to create high-risk levels, especially in important tasks. A strong success should speed up adoption. Finally, an open field in competition with semantic web technologies and most of the competitors mentioned not the technology, but the method of force. "The concept is the force on the small, traditional technologies such as programming languages and relational databases use a higher degree of knowledge to manage goals. This goal is the opposite, the procedure is a false economy, brand solutions, enterprise integration, and sharing. It is also an expensive method of maintenance when new opportunities arise, we will have a new disposable solution to create cycles. We also noted that the traditional existing technology investment had hidden costs. At last, as many people pointed out that cloud computing is the integration and data analysis enabled competitors. The method selects data management of our analysis. Several cited competitors are orthogonal and / or supply the functionality of the Semantic Web. It shows that to understand and compare to other methods, the Semantic Web missed the main products and services. Interestingly, the "force" seems like a viable option, the reality of big-time integration of missed data-efficient use of data is not the same, the more the attack continues the more the data speed grows. This provides an opening for dialogue in the future of the Semantic Web. On the contrary, it is considered that the semantic network is being abandoned, a new dialog box can carry out the progress in the future semantic website.

\section{Discussion and Conclusions}

This study provides a model of the proposed research from the perspective of IT that expects the strong support of Semantic Web technologies to explain the adopted organizations. From the technical part of the issue around the theoretical target (TOE), the model as a part of the Semantic Web used the individual structure of three technical dimensions (i.e., suitable for data management, simple and perceived use), two structures (i.e., the ability to innovate and the organization of data) (from the level of organization and two structures that support outside and competition in the industry). The environmental dimension applied to semantic web management data a remarkable effect.

\subsection{Findings of the study}

It is an environmental factor that indirectly affects the external support technology because the application data of the element's ease of use and management ability are passed through the Semantic Web. We can explain these results, as the technology, there is a standard that readily available for external assistance to help establish Semantic Web's processes and tools, and also for detecting a specific version of the capacity of effective business solutions. In other words, the technical possibilities for creating applications were received (a) to improve the perception of the relevant activities between ease of use of Semantic Web technologies and (b) to increase the capacity management of Semantic Web data and the organization of a two-folded effect on the Semantic Web. As another environmental factor, it's not only the competition in the industry but also through the innovative capacity of the organization and data with the Semantic Web powerful indirect effects. To confirm a positive relationship between the enterprise's innovation competitions in the same field, these results increase the investment in technologies such as Semantic Web technologies. The results show that the Semantic Web is to use perceived technical factors as an important factor for the adoption of the Semantic Web, in contrast to our expectations, ease of use does not appear on the Semantic Web as a significant impact. These comparative results of a possible explanation are the best professionals in the main concern that is the use of information Semantic Web, not their trust of the semantic web's main task is used to improve how easy the system uses advanced technology for business development. So, if they decide to spend on Semantic Web, the ease of use of Semantic Web technologies, it cannot be considered as an important factor. As an organizational unit, the enterprise data capacity is also an important factor in the impact of the introduction of the Semantic Web. This suggests the management of the current complex data is not necessarily a prerequisite for the use of the Semantic Web. The capacity of many existing enterprises' data (i.e., data warehousing, performance management dashboards, etc.) is linked to the company's ability and take advantage of the Semantic Web. In the semantic web's history, organizational innovation is the semantic web, with the provision of the most important factor for the semantic web, and with the coefficients of the maximum consideration. Furthermore, the results in Figure 4, the maximum effect of the semantic network (i.e. meaning) are used, although its performance at the same level is the data management. The results show that the innovation in the organization is the largest, and the performance of the semantic web perceived the ease of use, on the other hand, the most important determinant of the semantic web is not used, as they have a lower importance and performance than other structures. 
The semantic network with its esoteric logical approach is a complex technology with a constant change of the investment in the organization, in most cases, so that the challenge is difficult to use. The adoption of the technology is hard to believe that the key to the perceived value is available for organizations based on perceived value, often about its use of the challenge. An organization of a promising new technology is expected to be difficult to use. It can be difficult to use a threshold to form the most valuable competitive advantage in the competitive environment, as long as this perceived value is low in real terms.

\subsection{Practical and Theoretical Implications}

The results of this study provide important information, organizations can consider the semantic web's use. First of all, the strategic advantage of the semantic web can be increased relatively in the intensive competition organization in the industry. Compared with the relatively stable companies in the industry, the use of power is the various data's effectiveness for these enterprises to improve a greater competitive advantage. Therefore, the semantic web IPMA results show some management measures, such as improving the applicability of the data. Second, the business innovation level succeeds to introduce the technology and the semantic web develops effective restrictions on them. The semantic web is a new advanced technology, a high degree of ambiguity and requires further explorations, the economic value of the pocket. The results also provide examples of how semantic web service provides, the effects of possible priorities and the interests of its valued customers to distinguish. First, the suppliers in a competitive industry, such as the aim, target, these innovative organizations in the industries. Second, the supplier should not ignore the opportunity to target customers, they are not at the top of the current data functions. Third, there should be a supplier, your value proposition design focuses on how semantic web products to the needs of the customer, and objective data management is to maximize the performance of the applicability of the data. Fourth, the supplier should be stressed by their products of semantic web application development skills (standards, procedures, and tools); they can improve the applicability of the data management, semantic web capabilities of the organization must be followed. Fifth, suppliers confirm to ALS availability a possible obstacle, the stressed importance, and effectiveness by development aid benefits of products to improve the usability and overcome these barriers. Finally, the supplier is to coordinate better with the features of the big data solutions by web semantic, integrate solutions and methods of large data, we can do better in high compression with concrete solutions and the commercial semantic web functions will help to ensure that the different development in a plan of the underlying data. Some innovative competitions should continue to encourage big data solutions, also can offer semantic web support in this forum. Next, the importance of the research about providers and organizations, and these studies also contributed to theoretical research. First, the study proposes two ways to use to develop the Semantic Web: data flow management and relatively new Semantic Web structure. Semantic web site allows businesses to develop a model of consistent data content to archive data, improve the quality and consistency of content. It provides a standard level, the relationship between language and technology data in different formats, the data from different data sources to understand computers. Therefore, the main technical data of the Semantic Web technology is a unique feature. This reflects the applicability of data management. The role of the United Nations is one of the most important decisions for technological innovation and effective new technology, as web research to examine semantic. The extensions are directly to the other technical innovations. This technical innovation and degree is a principle host - boundary conditions or measures, innovation, organization, data on the impact of the oil industry, competition and may lead to the extension of performance or data link information may already have models Mishra et al. (2007). Second, a strong effect on both the availability of evident external support ease of use and the applicability of the data management enables the IT functions of the joint research to continue the line, a device has used to practice the appearance Benbasat and Barki (2007). In addition, the Semantic Web allows companies that their activities are not only to analyze unexpectedly efficient large amounts of data, but there are also new requirements without existing code to modify a dynamic adaptability. Semantic Web applications are beyond a clear demonstration of the practical value that can separate conventional techniques. This study, therefore, provides a unique perspective to organize a Semantic Web technology. We continue to study the application and interpretation of the results of further tests IPMA structural model. IPMA application of technology provides not only in areas such as an overview of the administration in terms of performance and importance but also opens up new avenues for future research.

\subsection{Limitations and Future Directions}

We also have the limits of this research. First, although the semantic web technologies are to reduce the limited by professional advice, the people cannot indeed understand the strategic and organizational factor. On the other hand, the study of the selective survey is limited at the meeting of the IOC and chief technology officer. Second, although the sample incorporate includes main decision-makers and employees, the introduction of new technologies, like the semantics website, is the best. It provides the true technology working, takes care of the knowledge and the result exceeds our efforts to promote. Third, this study is the use of the building up, direct or indirect semantic web technology. Other important factors, more researches are needed to other direction or indirection, for example, the factors Semantic web. For example, the privacy and security, trust, risks, and social implications and the quality of information are important and play an important role in the semantic web areas.

\section{References}

Abrahamson, E., \& Rosenkopf, L. (1997). Social network effects on the extent of innovation diffusion: A computer simulation. Organization Science, 8(3), 289-309. 
Alshamaila, Y., Papagiannidis, S., \& Li, F. (2013). Cloud computing adoption by SMEs in the north east of England: A multiperspective framework. Journal of Enterprise Information Management, 26(3), 250-275.

Anderson, J. C., \& Gerbing, D. W. (1988). Structural equation modeling in practice: A review and recommended two-step approach. Psychological Bulletin, 103(3), 411.

Angst, C. M., \& Agarwal, R. (2009). Adoption of electronic health records in the presence of privacy concerns: The elaboration likelihood model and individual persuasion. MIS Quarterly, 33(2), 339-370.

Au, Y. A., AU, Y. A., \& KAUFFMAN, R. J. (2003). What do you know? Rational expectations in information technology adoption and investment. Journal of Management Information Systems, 20(2), 49-76.

Bayerl, S., Lauche, K., \& Axtell, C. (2016). Revisiting group-based technology adoption as a dynamic process: The role of changing attitude-rationale configurations. Mis Quarterly, 40(3), 775-784.

Benbasat, I., \& Barki, H. (2007). Quo vadis TAM? Journal of the Association for Information Systems, 8(4), 7.

Bera, P., Burton-Jones, A., \& Wand, Y. (2011). Guidelines for designing visual ontologies to support knowledge identification. Mis Quarterly, 883-908.

Berners-Lee, T. (2000). Semantic Web on XML, Keynote presentation for XML 2000. Slides available at: http://www. w3. org/2000/Talks/1206-xml2k-tbl/slide1-0. html. Reporting available at: http://www. xml. com/pub/a/2000/12/xml2000/timbl. html.

Berners-Lee, T., Hendler, J., \& Lassila, O. (2001). The semantic web. Scientific American, 284(5), 28-37.

Bizer, C., Lehmann, J., Kobilarov, G., Auer, S., Becker, C., Cyganiak, R., \& Hellmann, S. (2009). DBpedia-A crystallization point for the Web of Data. Journal of Web Semantics, 7(3), 154-165.

Brickley, D., Guha, R. V., \& McBride, B. (2004). RDF vocabulary description language 1.0: RDF Schema. W3C Recommendation (2004). URL http://www. w3. org/tr/2004/rec-rdf-schema-20040210.

Bruque-Cámara, S., Vargas-Sánchez, A., \& Hernández-Ortiz, M. J. (2004). Organizational determinants of IT adoption in the pharmaceutical distribution sector. European Journal of Information Systems, 13(2), 133-146.

Calisir, F., \& Calisir, F. (2004). The relation of interface usability characteristics, perceived usefulness, and perceived ease of use to end-user satisfaction with enterprise resource planning (ERP) systems. Computers in Human Behavior, 20(4), 505515.

CDATA-Rogers, E. (1995). Diffusion of innovations. In: New York: Free Press.

Chang, I.-C., Hwang, H.-G., Hung, M.-C., Lin, M.-H., \& Yen, D. C. (2007). Factors affecting the adoption of electronic signature: Executives' perspective of hospital information department. Decision Support Systems, 44(1), $350-359$.

Chau, P. Y., \& Tam, K. Y. (1997). Factors affecting the adoption of open systems: an exploratory study. MIS quarterly, 1-24.

Chen, J., \& McQueen, R. J. (2008). Factors affecting e-commerce stages of growth in small Chinese firms in New Zealand: an analysis of adoption motivators and inhibitors. Journal of Global Information Management (JGIM), 16(1), 26-60.

Choi, J., Nazareth, D. L., \& Jain, H. K. (2010). Implementing service-oriented architecture in organizations. Journal of Management Information Systems, 26(4), 253-286.

Chou, C.-H., Zahedi, F. M., \& Zhao, H. (2014). Ontology-Based Evaluation of Natural Disaster Management Websites: A Multistakeholder Perspective. Mis Quarterly, 38(4), 997-1016.

Chwelos, P., Benbasat, I., \& Dexter, A. S. (2001). Empirical test of an EDI adoption model. Information systems research, 12(3), 304-321.

D'Aubeterre, F., Singh, R., \& Iyer, L. (2008). A Semantic Approach to Secure Collaborative Inter-Organizational eBusiness Processes*(SSCIOBP). Journal of the Association for Information Systems, 9(3/4), 231.

Danneels, E. (2002). The dynamics of product innovation and firm competences. Strategic management journal, 23(12), 1095-1121.

Davis, F. D. (1989). Perceived usefulness, perceived ease of use, and user acceptance of information technology. MIS quarterly, 319-340.

Dean, M., \& Schreiber, G. (2004). OWL Web Ontology Language Reference: http://www. w3. org. Retrieved from

Fan, H., \& Gui, H. (2007). Study on heterogeneous data integration issues in web environments. Paper presented at the 2007 International Conference on Wireless Communications, Networking and Mobile Computing.

Fan, W., Chen, Z., Xiong, Z., \& Chen, H. (2012). The Internet of data: a new idea to extend the IOT in the digital world. Frontiers of Computer Science, 6(6), 660-667.

Fishbein, M. A., \& Ajzen, I. (2011). I.(1975). Belief, attitude, intention and behaviour: An introduction to theory and research. Reading, Addison-Wesley.

Forman, C. (2005). The corporate digital divide: Determinants of Internet adoption. Management Science, 51(4), $641-654$.

Fornell, C., \& Larcker, D. F. (1981). Evaluating structural equation models with unobservable variables and measurement error. Journal of Marketing Research, 18(1), 39-50.

Gagnon, M. (2007). Ontology-based integration of data sources. Paper presented at the 2007 10th International Conference on Information Fusion.

Gliozzo, A., Biran, O., Patwardhan, S., \& McKeown, K. (2013). Semantic technologies in IBM Watson. Paper presented at the Proceedings of the Fourth Workshop on Teaching NLP and CL.

Hair Jr, J. F., Hult, G. T. M., Ringle, C., \& Sarstedt, M. (2016). A primer on partial least squares structural equation modeling (PLS-SEM): Sage publications.

Hepp, M. (2008). Goodrelations: An ontology for describing products and services offers on the web. Paper presented at the International Conference on Knowledge Engineering and Knowledge Management. 
Hong, S.-J., \& Tam, K. Y. (2006). Understanding the adoption of multipurpose information appliances: The case of mobile data services. Information Systems Research, 17(2), 162-179.

Hsu, C.-L., Lu, H.-P., \& Hsu, H.-H. (2007). Adoption of the mobile Internet: An empirical study of multimedia message service (MMS). Omega, 35(6), 715-726.

Hsu, I.-C. (2013). Personalized web feeds based on ontology technologies. Information Systems Frontiers, 15(3), 465-479.

Iacovou, C. L., Benbasat, I., \& Dexter, A. S. (1995). Electronic data interchange and small organizations: adoption and impact of technology. MIS Quarterly, 465-485.

Igbaria, M., Zinatelli, N., Cragg, P., \& Cavaye, A. L. (1997). Personal computing acceptance factors in small firms: A structural equation model. MIS quarterly, 21(3).

Jeyaraj, A., Rottman, J. W., \& Lacity, M. C. (2006). A review of the predictors, linkages, and biases in IT innovation adoption research. Journal of Information Technology, 21(1), 1-23.

Khoumbati, K., Themistocleous, M., \& Irani, Z. (2006). Evaluating the adoption of enterprise application integration in healthcare organizations. Journal of Management Information Systems, 22(4), 69-108.

Kim, G., \& Suh, Y. (2011). Semantic business process space for intelligent management of sales order business processes. Information Systems Frontiers, 13(4), 515-542.

Kim, H., Fox, M. S., \& Sengupta, A. (2007). How To Build Enterprise Data Models To Achieve Compliance To Standards Or Regulatory Requirements (and share data). Journal of the Association for Information Systems, 8(2), 5.

Klein, M., Broekstra, J., Fensel, D., van Harmelen, F., \& Horrocks, I. (2003). Ontologies and schema languages on the web. Spinning the Semantic Web: Bringing the World Wide Web to its full potential, 95-140.

Kuan, K. K., \& Chau, P. Y. (2001). A perception-based model for EDI adoption in small businesses using a technologyorganization-environment framework. Information \& Management, 38(8), 507-521.

Lee, C.-P., \& Shim, J. P. (2007). An exploratory study of radio frequency identification (RFID) adoption in the healthcare industry. European Journal of Information Systems, 16(6), 712-724.

Lee, J. (2004). Discriminant analysis of technology adoption behavior: a case of internet technologies in small businesses. Journal of Computer Information Systems, 44(4), 57-66.

Lim, K. H. (2009). Knowledge management systems diffusion in Chinese enterprises: A multistage approach using the technology-organization-environment framework. Journal of Global Information Management (JGIM), 17(1), 70-84.

Lin, A., \& Chen, N.-C. (2012). Cloud computing as an innovation: Percepetion, attitude, and adoption. International Journal of Information Management, 32(6), 533-540.

Livenson, I., \& Laure, E. (2011). Towards transparent integration of heterogeneous cloud storage platforms. Paper presented at the Proceedings of the fourth international workshop on Data-intensive distributed computing.

MacKenzie, S. B., \& Podsakoff, P. M. (2012). Common method bias in marketing: causes, mechanisms, and procedural remedies. Journal of Retailing, 88(4), 542-555.

Mishra, A. N., \& Agarwal, R. (2010). Technological frames, organizational capabilities, and IT use: An empirical investigation of electronic procurement. Information Systems Research, 21(2), 249-270.

Mishra, A. N., Konana, P., \& Barua, A. (2007). Antecedents and consequences of internet use in procurement: an empirical investigation of US manufacturing firms. Information Systems Research, 18(1), 103-120.

Moore, G. C., \& Benbasat, I. (1991). Development of an instrument to measure the perceptions of adopting an information technology innovation. Information Systems Research, 2(3), 192-222.

Oliveira, T., \& Martins, M. F. (2010). Understanding e-business adoption across industries in European countries. Industrial Management \& Data Systems, 110(9), 1337-1354.

Oliveira, T., Thomas, M., \& Espadanal, M. (2014). Assessing the determinants of cloud computing adoption: An analysis of the manufacturing and services sectors. Information \& Management, 51(5), 497-510.

Pan, M.-J., \& Jang, W.-Y. (2008). Determinants of the adoption of enterprise resource planning within the technologyorganization-environment framework: Taiwan's communications industry. Journal of Computer information systems, 48(3), 94-102.

Petty, R. E., \& Cacioppo, J. T. (1981). Attitudes and persuasion: classic and contemporary approaches, Wm. C. Brown, Dubuque, IA.

Pick, J. B., \& Azari, R. (2011). A global model of technological utilization based on governmental, business-investment, social, and economic factors. Journal of Management Information Systems, 28(1), 49-84.

Podsakoff, P. M., MacKenzie, S. B., Lee, J.-Y., \& Podsakoff, N. P. (2003). Common method biases in behavioral research: A critical review of the literature and recommended remedies. Journal of Applied Psychology, 88(5), 879.

Porter, M. E. (1985). Competitive advantage. New York.

Premkumar, G., Ramamurthy, K., \& Nilakanta, S. (1994). Implementation of electronic data interchange: an innovation diffusion perspective. Journal of Management Information Systems, 11(2), 157-186.

Premkumar, G., \& Roberts, M. (1999). Adoption of new information technologies in rural small businesses. Omega, 27(4), 467-484.

Rahi, S., Ghani, M., Alnaser, F., \& Ngah, A. (2018). Investigating the role of unified theory of acceptance and use of technology (UTAUT) in internet banking adoption context. Management Science Letters, 8(3), 173-186.

Saadé, R., \& Bahli, B. (2005). The impact of cognitive absorption on perceived usefulness and perceived ease of use in online learning: an extension of the technology acceptance model. Information \& Management, 42(2), 317-327. 
Shih, D.-H., Chiu, Y.-W., Chang, S.-I., \& Yen, D. C. (2008). An empirical study of factors affecting RFID's adoption in Taiwan. Journal of Global Information Management (JGIM), 16(2), 58-80.

Simon, K. D. (2005). The value of open standards and open-source software in government environments. IBM Systems Journal, 44(2), 227-238.

Tan, M., \& Teo, T. S. (2000). Factors influencing the adoption of Internet banking. Journal of the Association for information Systems, 1(1), 5.

Teo, T. S., \& Pian, Y. (2003). A contingency perspective on Internet adoption and competitive advantage. European Journal of Information Systems, 12(2), 78-92.

Themistocleous, M. (2004). Justifying the decisions for EAI implementations: a validated proposition of influential factors. Journal of Enterprise Information Management, 17(2), 85-104.

Thong, J. Y. (1999). An integrated model of information systems adoption in small businesses. Journal of Management Information Systems, 15(4), 187-214.

Tidd, J., \& Bessant, J. R. (2018). Managing innovation: integrating technological, market and organizational change: John Wiley \& Sons.

Tornatzky, L. G., Fleischer, M., \& Chakrabarti, A. (1990). The processes of technological innovation. Issues in organization and management series. Lexington Books. Available at http://www. amazon. com/Processes-Technological-InnovationOrganization/Management/dp/0669203483. Accessed June, 10, 2013.

Umar, A., \& Zordan, A. (2009). Enterprise ontologies for planning and integration of business: a pragmatic approach. IEEE Transactions on Engineering Management, 56(2), 352-371.

Venkatesh, V., \& Davis, F. D. (2000). A theoretical extension of the technology acceptance model: Four longitudinal field studies. Management Science, 46(2), 186-204.

Venkatesh, V., Morris, M. G., Davis, G. B., \& Davis, F. D. (2003). User acceptance of information technology: Toward a unified view. MIS Quarterly, 425-478.

Wang, S., \& Wang, H. (2012). Organizational schemata of e-portfolios for fostering higher-order thinking. Information Systems Frontiers, 14(2), 395-407.

Wang, Y.-M., Wang, Y.-S., \& Yang, Y.-F. (2010). Understanding the determinants of RFID adoption in the manufacturing industry. Technological Forecasting and Social Change, 77(5), 803-815.

Wejnert, B. (2002). Integrating models of diffusion of innovations: A conceptual framework. Annual Review of Sociology, 28(1), 297-326.

Wu, F., Zsidisin, G., \& Ross, A. (2007). Antecedents and outcomes of e-procurement adoption: an integrative model. IEEE Transactions on Engineering Management, 54(3), 576-587.

Xue, L., Ray, G., \& Sambamurthy, V. (2012). Efficiency or innovation: How do industry environments moderate the effects of firms' IT asset portfolio? Mis Quarterly, 36(2).

Zhu, K., Kraemer, K., \& Xu, S. (2003). Electronic business adoption by European firms: a cross-country assessment of the facilitators and inhibitors. European Journal of Information Systems, 12(4), 251-268.

Zhu, K., \& Kraemer, K. L. (2005). Post-adoption variations in usage and value of e-business by organizations: cross-country evidence from the retail industry. Information Systems Research, 16(1), 61-84.

Zhu, K., Kraemer, K. L., \& Dedrick, J. (2004). Information technology payoff in e-business environments: An international perspective on value creation of e-business in the financial services industry. Journal of Management Information Systems, 21(1), 17-54.

Zhu, K., Kraemer, K. L., \& Xu, S. (2006). The process of innovation assimilation by firms in different countries: a technology diffusion perspective on e-business. Management Science, 52(10), 1557-1576.

Ziegler, P., \& Dittrich, K. R. (2004). Three decades of data intecration-All problems solved? In Building the Information Society (pp. 3-12): Springer.

\section{Appendix A}

Questionnaires

\begin{tabular}{|c|c|}
\hline Construct & Measures \\
\hline \multirow{3}{*}{$\begin{array}{l}\text { Availability of External } \\
\text { Support }\end{array}$} & ES1: The Semantic Web maintains effective standards. ES2: The existing useful tools \\
\hline & for the Semantic Web. \\
\hline & ES3: The existing useful development methods for the Semantic Web. \\
\hline \multirow[t]{2}{*}{$\begin{array}{l}\text { Industry Competi- } \\
\text { tion }\end{array}$} & $\begin{array}{l}\text { IC1: The industry maintains a high growth rate. IC2: The industry is considered } \\
\text { competitive. }\end{array}$ \\
\hline & IC3: The industry is global. \\
\hline \multirow[t]{2}{*}{$\begin{array}{l}\text { Applicability to Data Man- } \\
\text { agement }\end{array}$} & $\begin{array}{l}\text { DM1: The Semantic Web is applicable for data integration solutions. DM2: The Semantic Web is applica- } \\
\text { ble for data analysis solutions. }\end{array}$ \\
\hline & DM3: The Semantic Web applies to data quality solutions. \\
\hline \multirow[t]{3}{*}{ Perceived Ease of Use } & EOU1: The Semantic Web is easy to use. \\
\hline & EOU2: The Semantic Web is easy to learn how to use. EOU3: The Semantic Web \\
\hline & EOU4: The Semantic Web is easy to apply to data challenges. \\
\hline \multirow{2}{*}{$\begin{array}{l}\text { Perceived Useful- } \\
\text { ness }\end{array}$} & PU1: The Semantic Web is an updated technology. \\
\hline & $\begin{array}{l}\text { PU2: The Semantic Web maintains effective standards. PU3: Semantic Web solutions } \\
\text { are cost-effective. }\end{array}$ \\
\hline
\end{tabular}




\begin{tabular}{|c|c|}
\hline & PU4: Semantic Web solutions are timely to develop. \\
\hline $\begin{array}{l}\text { Organization's Innova- } \\
\text { tiveness }\end{array}$ & $\begin{array}{l}\text { IN1: My organization is innovative. } \\
\text { IN2: My organization depends on innovation. IN3: My management en- } \\
\text { courages innovation. } \\
\text { IN4: My organization has the appropriate skills set for innovation. }\end{array}$ \\
\hline $\begin{array}{l}\text { Organization's Data Ca- } \\
\text { pability }\end{array}$ & $\begin{array}{l}\text { DC1: My organization is capable of data analysis. DC2: My organization is capable } \\
\text { of integrating data. } \\
\text { DC3: My organization is capable of innovating data. } \\
\text { DC4: My organization is capable of delivering data when needed. }\end{array}$ \\
\hline $\begin{array}{l}\text { Semantic Web Adop- } \\
\text { tion }\end{array}$ & $\begin{array}{l}\text { ADO1: We will decide to use the Semantic Web soon } \\
\text { ADO2: We intend to use the Semantic Web in the future. }\end{array}$ \\
\hline Data Complexity & $\begin{array}{l}\text { DC1: My organization maintains diverse data technologies and data structures. } \\
\text { DC2: My organization's data technologies and data structures are unstable. }\end{array}$ \\
\hline
\end{tabular}

\section{Appendix B}

Confirmatory Factor Analysis Result

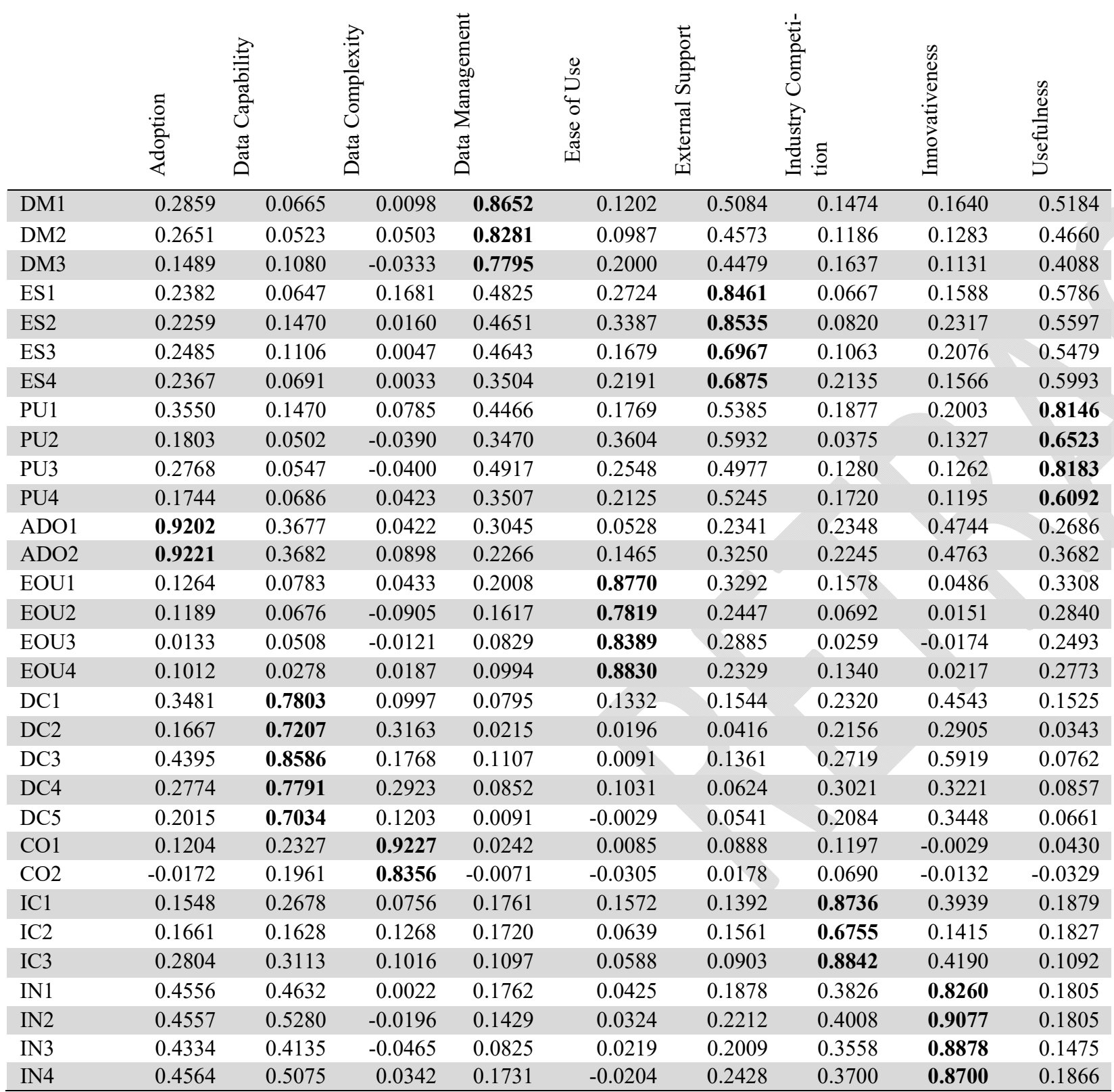


(C) 2020 by the authors; licensee Growing Science, Canada. This is an open access article distributed under the terms and conditions of the Creative Commons Attribution (CC-BY) license (http://creativecommons.org/licenses/by/4.0/). 